\title{
Secular Variation in Rainfall and Intensity-Frequency-Duration Curves in \\ Eastern Australia
}

\author{
Yi-Ru Chen \\ Griffith University, School of Engineering, Gold Coast, Queensland 4222 Australia \\ Telephone: +61755527608 \\ Facsimile: +61737357404 \\ E-mail: yi-ru.chen@griffith.edu.au \\ Bofu Yu \\ Griffith University, School of Engineering, Gold Coast, Queensland 4222 Australia \\ E-mail: b.yu@griffith.edu.au \\ Graham Jenkins \\ Griffith University, School of Engineering, Gold Coast, Queensland 4222 Australia \\ E-mail: graham.jenkins@ griffith.edu.au
}

\begin{abstract}
Rainfall intensity-frequency-duration curves are used extensively for storm runoff estimation. It is generally assumed that rainfall intensity would increase with global warming irrespective of the underlying changes to rainfall. This study analyzed rainfall and temperature from 6 sites in Eastern Australia. Two non-overlapping 30-year periods with the greatest difference in the mean annual rainfall were selected at each of the 6 sites to test for significant changes in the mean annual temperature and rainfall. Changes in the mean rainfall intensity for different frequencies of occurrence and storm durations for each site were also analyzed. Temperature has increased at all sites, and significantly at 5 out of the 6 sites. The mean annual rainfall has significantly changed between the two non-overlapping periods at the sites with the exception of Cairns (latitude $-16.87^{\circ}$ south). The changes in rainfall intensity for longer durations ( $\geq 1 \mathrm{hr}$ ) positively correlate with changes in the mean annual rainfall. There is evidence to suggest that the 6 minutes rainfall intensity would increase in irrespective of the changes in the mean annual rainfall.
\end{abstract}

Keywords: rainfall variation, extreme rainfall, intensity frequency duration, Eastern Australia 
Secular variation in rainfall in Eastern Australia

\section{Introduction}

Rainfall intensity-frequency-duration (IFD) relationships are widely used in engineering designs, such as stormwater drainage systems, bridges and dams, to estimate storm runoff volumes and peak runoff rates (Endreny and Imbeah 2009; Pilgrim 2001). Future rainfall is expected to increase in its intensity and/or frequency of occurrence, and storm duration may be shortened as a consequence of climate change (Trenberth 1998, 1999; Trenberth et al. 2003). An increase in global temperature in a $\mathrm{CO}_{2}$-warmed world would lead to an increase in moisture in the atmosphere, which could possibly increase the rate of precipitation (Trenberth 1998). Current research reported in the literature suggests that storm durations could be shorter and the rainfall intensity could be higher in the future. Therefore, current infrastructure based on the existed IFD relationships may be inadequate during extreme events under future climate conditions.

The likely change in heavy rainfall can be estimated using General Circulation Models (GCMs) output and/or from statistical analysis of historical weather observations (Blenkinsop et al. 2009). Examinations of long term historical heavy rainfall can provide a better understanding of past climate change and help inform likely future climate change scenarios. Changes in heavy rainfall and annual rainfall have been investigated in several regions in the world (Cannarozzo et al. 2006; Groisman et al. 2005; Krishnakumar et al. 2009). Their results show that changes in heavy rainfall are more significant than those in annual rainfall (Groisman et al. 2005; Trenberth et al. 2003). Groisman et al. (2005) examined the trends in heavy rainfall around the world and found that some regions had experienced an increase in heavy rainfall, but for these regions there was either no change in annual rainfall, or even a decrease in annual rainfall.

Many studies have also examined rainfall variations around Australia (Haylock and Nicholls 2000; Li et al. 2011; Lough 1991, 1993, 1997; Nicholls 2003; Nicholls and Kariko 
1993; Nicholls et al. 1996; Suppiah 1993; Suppiah and Hennessy 1998; Yu and Neil 1993). Suppiah and Hennessy (1998) noted that heavy daily rainfall decreased in southwest Australia from 1910 to 1990. Haylock and Nicholls (2000) examined the trends in Australian extreme rainfall in 1910-1998, and found that the intensity (mm/day) of the four most extreme rainfall events per year had increased in Eastern and Southern Australia. Nicholls and Kariko (1993) used five rainfall stations in Eastern Australia from 1910 to 1988 and found that the variation in annual rainfall was highly related to the variation in intensity (mm/day). Nicholls et al. (1996) examined the relationship between the spatial average annual rainfall and temperature for Australia from 1910 to 1992 by applying the Theissen polygon coefficients. A significant negative correlation between maximum temperature and annual rainfall was found in their study. This correlation was based on spatial averages which minimized variations within regions. The aforementioned studies examined the changes in annual, seasonal, monthly and daily rainfall. However, changes in short duration rainfall, for example sub-daily, have not been tested in Eastern Australia.

The Australian Bureau of Meteorology (BOM) is currently undertaking an IFD Design Rainfall Revision project, which will include almost 30 years of additional rainfall data (Green et al. 2012, Johnson et al. 2012). Once the revised IFDs are released, the differences between the revised IFDs and the existing IFDs can be used to inform how recent climate change and variations might have affected the design of flood estimations.

This research aims to examine the relationships between rainfall and temperature, and between mean annual rainfall and extreme rainfall of short durations. The research seeks to determine whether there have been significant changes in annual rainfall and temperature and whether short-duration rainfall intensities are correlated with both annual rainfall and temperature in Eastern Australia. In particular, this research attempts (1) to establish IFD curves for two 
periods in the past 100 years that have the greatest contrast in the mean annual rainfall; (2) to understand the changes in rainfall intensity for different durations between these two periods; and (3) to investigate the relationship between changes in the mean temperature, annual rainfall and rainfall intensities.

\section{Data and Methods}

Six sites in Eastern Australia were chosen in this study for sub-hourly rainfall analysis, as shown in Figure 1. As 30-year is a standard period for the estimation of climatic variables characterizing, therefore two pairs of 30-year climatology were identified for each study site.. Each period was selected to represent the highest and lowest 30-year mean annual rainfall on record for each site. Table 1 shows the climate classifications (Harvey et al. 2000) and the 2 selected periods for each site. The pluviograph data at 6 minutes of interval from the BOM, were used in this study. Average rainfall intensities were derived for 6, 30 minutes, 1, 2, 3, 6, 12 and 24 hours durations at each site, as suggested by Canterford et al. (2001).

Analysis of the pluviograph records indicated some missing data for some events. It appeared that much of the missing data occurred at either the beginning or end of the events. Consequently, the daily rainfall was used in this study to analyse rainfall duration of 24 hours. The daily rainfall is recorded from 9AM to 9AM in Australia. The total daily rainfall may be lower than a continuous 24 hours of total rainfall from pluviograph data, but the former is much more consistent and easy to define.

The Annual Maximum Series (AMS) and the Partial Duration Series (PDS) are the most commonly used methods for deriving the IFD (Takeuchi, 1984). The AMS selects the maximum rainfall intensity in each calendar year, whereas, the PDS chooses the highest rainfall intensity 
that exceeds a threshold over the entire period. The AMS is a more popular approach in hydrological studies compared to the PDS, because extraction of the PDS is not straightforward (Xuereb and Green 2012). The disadvantages of the PDS are that it may suffer from independent issues and threshold selections and also it may miss some small events. The advantages of using the AMS are that it is a simple approach and more objective compared with the PDS. However, the disadvantage of the AMS is that the sampling is limited by the calendar year which may result in small sample sizes and affect parameter estimations for extreme rainfall distributions. Srikanthan (2012) argued that the AMS is simple and easy to apply and it is as efficient as the PDS in many respects. On balance, AMS is the preferred method, and adopted for this study.

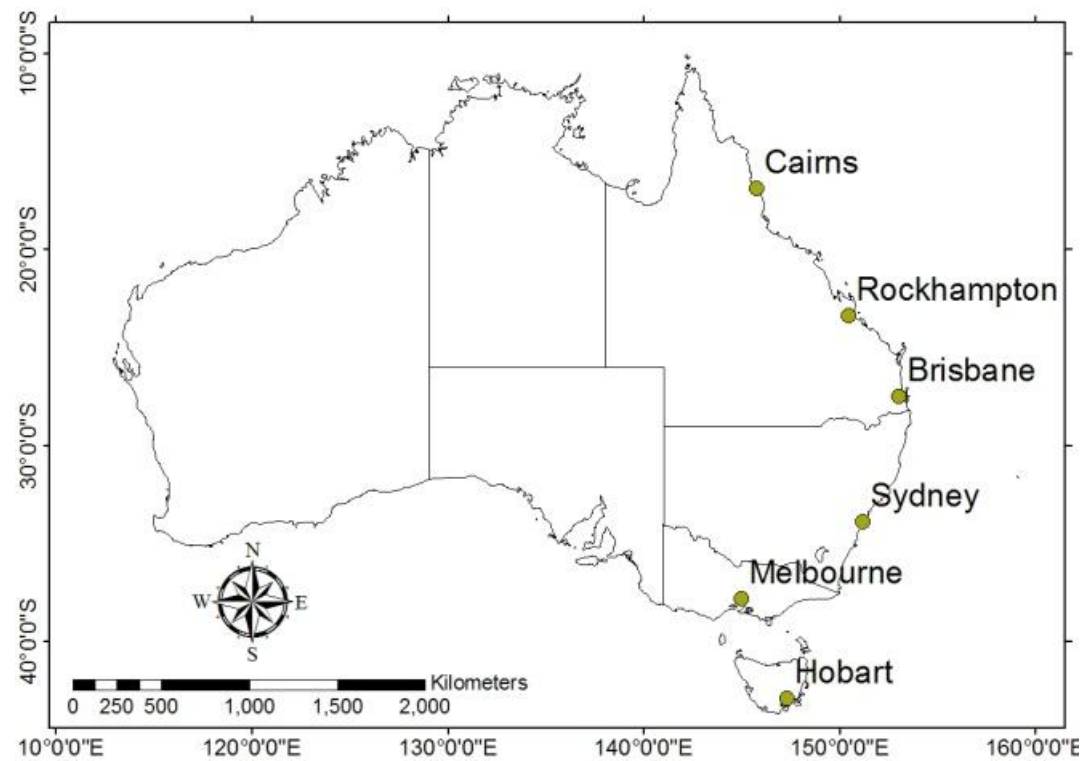

Figure 1 Location map of the 6 sites in Eastern Australia.

Table 1. Pluviograph stations, climate zones and two contrasting periods.

\begin{tabular}{cccc}
\hline Location & Clim. zone & P1 & P2 \\
\hline Cairns & Tropical & $1943-1972$ & $1973-2002$ \\
Rockhampton & Sub-tropical & $1946-1975$ & $1976-2005$ \\
Brisbane & Sub-tropical & $1912-1941$ & $1947-1976$ \\
Sydney & Temperate & $1921-1950$ & $1951-1980$ \\
Melbourne & Temperate & $1946-1975$ & $1976-2005$ \\
Hobart & Temperate & $1931-1960$ & $1975-2004$ \\
\hline
\end{tabular}


The Average Recurrence Interval (ARI), by definition, is the reciprocal of the probability that the event would be exceeded in any one year. Though estimating IDF curves for a greater year ARI, e.g. 100 year ARI, could be a good indicator of trends in for large floods, this would require extrapolation as the record length is 30 years. For empirical evidence based observations 2 and 20 year ARIs were used for the purpose of this study.

The log-Pearson Type III (LPT3) distribution is the standard distribution for frequency analyses in the United States (Chow et al. 1988). It was also recommended by the Institution of Engineers, Australia (I.E.A.) for design rainfall in Australia (Canterford et al. 2001). However, the LPT3 is no longer recommended by the I.E.A. (Rahman et al. 2009) as they have found that the Generalised Extreme Value (GEV) distribution is more suitable for frequency analyses in Australia. Thought there are alternatives to estimate IDF curves, it does not make a significant difference when estimating IDF curves for 2 and 20 year ARIs as they are intended for small floods. Since the frequency factors are provided, the LPT3 is straight forward to compute and for this reason it was used in this study. The log-Pearson Type III rainfall intensity (Chow et al. 1988, Pilgrim 2001) is obtained from:

$$
I_{D}^{Y}=10^{\left(M+K_{T} S\right)}
$$

Where $I_{D}^{Y}$ is the rainfall intensity for ARI of $Y$ (year) and duration $D$ (hour), $M$ and $S$ are the mean and standard deviation of the logarithms of the primary rainfall intensities, and $\mathrm{K}_{\mathrm{T}}$ is the frequency factors from Pilgrim and Doran (2001).

The mean annual rainfall, temperature, rainfall intensities for a range of durations, and 2 ARIs were calculated for the two contrasting periods. IFD curves were prepared for visual examination for each of the 6 sites. The T-test was used to infer statistically significant differences in the mean for these variables between the two contrasting periods. Empirical relationships among changes 
in the mean annual rainfall, short duration extreme rainfall, and mean temperature were sought for these 6 sites in Eastern Australia.

\section{Results and Discussion}

The IFD curves for 2- and 20- year ARIs are shown in Figure 2. Each curve corresponds to a specific ARI for a 30-year period. Unlike the IFD curves that can be obtained from the BOM (Australian Bureau of Meteorology 2011), this study only plots the curves for durations of up to 24 hours.

As can be seen in Figure 2, rainfall intensities show a greater variation between the two contrasting periods and for the two selected ARIs at the higher latitudes (e.g. Melbourne, and Hobart) than those at other locations. A paired test (results not included) indicated that there were no consistent and significant changes in rainfall intensities between these IFD curves from these non-overlapping 30-year climatologies. Further, changes in the rainfall intensity varied depending on the storm duration for the 6 sites tested. 

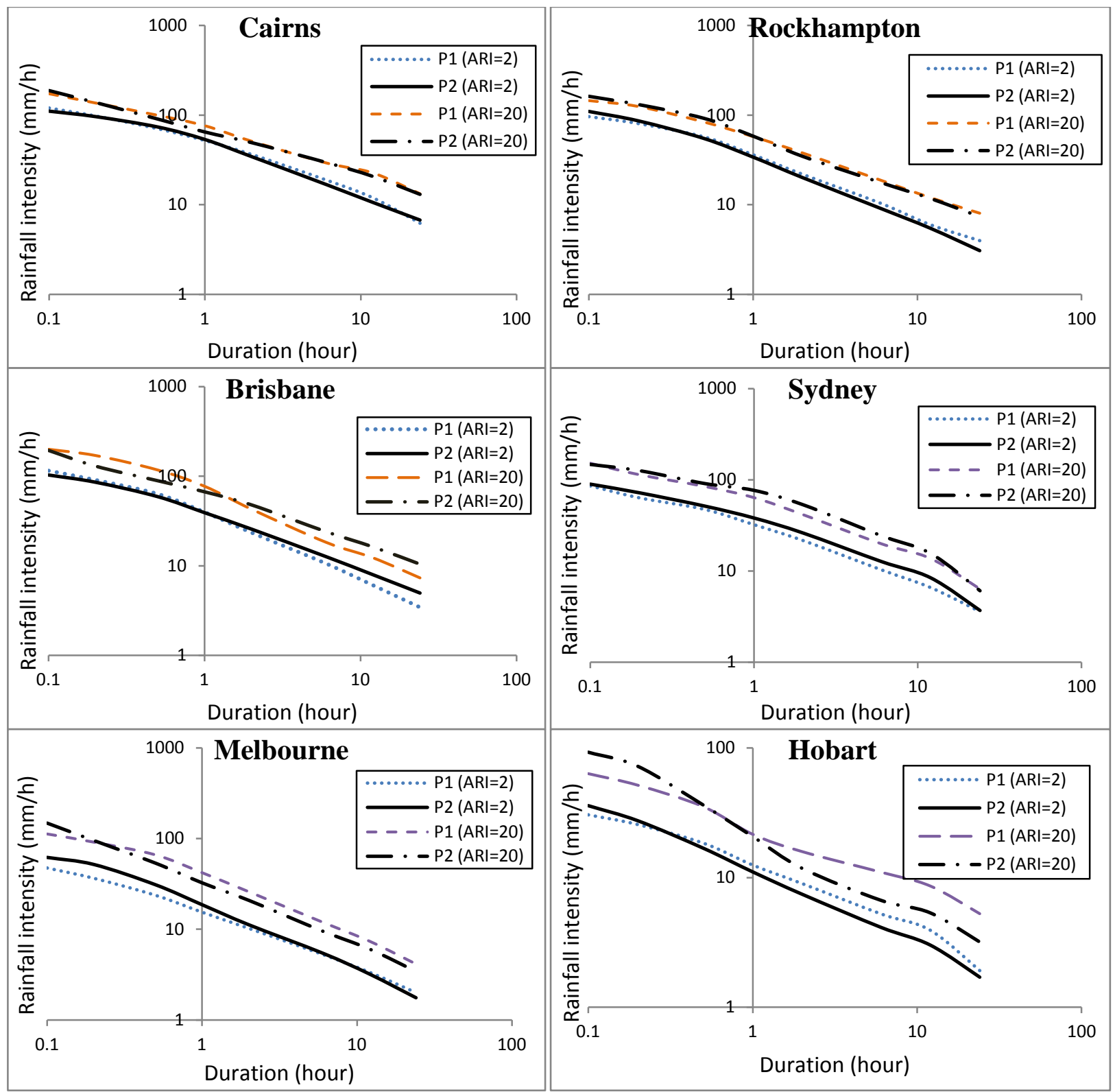

Figure 2 IDF for 2 and 20-year return periods

The T-test was applied to the mean temperature, annual rainfall and rainfall intensities between the two contrasting periods (Table 2). Those with a $p$-value less than 0.05 are highlighted in Table 2. The annual rainfall in P1 was found to be statistically different to that in P2 for all locations in Eastern Australia apart from Cairns. Sydney, Brisbane and Cairns had less mean annual rainfall in P1 than in P2; Rockhampton, Melbourne and Hobart had higher mean annual 
rainfall in P1. The mean annual temperature in P1 was found to be significantly higher than that in $\mathrm{P} 2$ for all locations apart from Brisbane. Although the mean annual temperature in Cairns significantly increased from $\mathrm{P} 1$ to $\mathrm{P} 2$, annual rainfall and rainfall intensities did not change over this time at this tropical site.

Table 2 Statistics of mean 30-year temperature and annual rainfall, and rainfall intensities for the 2 contrasting periods (Mean 1 and 2 refer to the mean values in P1 and P2, shade and bold are those with $\mathrm{P}$-values $\leq 0.05$ )

\begin{tabular}{|c|c|c|c|c|c|c|c|c|c|c|c|}
\hline Location & Statistics & Temp. & Annual & $6 \mathrm{~min}$ & $30 \mathrm{~min}$ & $1 \mathrm{hr}$ & $2 \mathrm{hr}$ & $3 \mathrm{hr}$ & $6 \mathrm{hr}$ & $12 \mathrm{hr}$ & $24 \mathrm{hr}$ \\
\hline \multirow{5}{*}{ Cairns } & Mean-1 & 24.7 & 1953 & 117.8 & 68.4 & 50.8 & 35.0 & 27.3 & 18.5 & 12.4 & 6.9 \\
\hline & Mean-2 & 24.9 & 2067 & 116.3 & 70.7 & 52.2 & 35.1 & 27.8 & 18.1 & 11.5 & 7.3 \\
\hline & Change & $0.2^{\circ} \mathrm{C}$ & $+6 \%$ & $-1 \%$ & $+3 \%$ & $+3 \%$ & $0 \%$ & $2 \%$ & $-2 \%$ & $-7 \%$ & $+6 \%$ \\
\hline & $t$-test & 2.30 & 0.82 & 0.15 & 0.48 & 0.41 & 0.04 & 0.23 & 0.27 & 0.65 & 0.52 \\
\hline & P-value & 0.013 & 0.208 & 0.439 & 0.316 & 0.343 & 0.483 & 0.406 & 0.395 & 0.260 & 0.301 \\
\hline \multirow{5}{*}{ Rockhampton } & Mean-1 & 22.2 & 871 & 98.1 & 57.9 & 37.2 & 23.0 & 17.5 & 211.0 & 6.5 & 4.3 \\
\hline & Mean-2 & 22.8 & 732 & 112.9 & 58.6 & 36.8 & 21.6 & 16.5 & 9.9 & 6.1 & 3.6 \\
\hline & Change & $0.6^{\circ} \mathrm{C}$ & $-19 \%$ & $+15 \%$ & $+1 \%$ & $-1 \%$ & $-6 \%$ & $-6 \%$ & $-10 \%$ & $-7 \%$ & $-17 \%$ \\
\hline & $t$-test & 6.09 & 1.87 & 2.17 & 0.16 & 0.15 & 0.74 & 0.66 & 1.06 & 0.59 & 1.52 \\
\hline & P-value & $<0.01$ & 0.033 & 0.017 & 0.437 & 0.442 & 0.233 & 0.256 & 0.147 & 0.279 & 0.068 \\
\hline \multirow{5}{*}{ Brisbane } & Mean-1 & 20.5 & 1016 & 122.5 & 68.9 & 43.8 & 25.5 & 18.6 & 11.3 & 6.7 & 3.9 \\
\hline & Mean-2 & 20.6 & 1239 & 112.4 & 60.1 & 41.1 & 27.6 & 21.6 & 13.9 & 8.8 & 5.6 \\
\hline & Change & $0.1^{\circ} \mathrm{C}$ & $+22 \%$ & $-8 \%$ & $-13 \%$ & $-6 \%$ & $+8 \%$ & $16 \%$ & $+23 \%$ & $+31 \%$ & $+44 \%$ \\
\hline & $t$-test & 1.61 & 2.62 & 0.91 & 1.59 & 0.66 & 0.84 & 1.59 & 2.20 & 2.34 & 3.00 \\
\hline & P-value & 0.057 & 0.006 & 0.183 & 0.059 & 0.256 & 0.203 & 0.059 & 0.016 & 0.012 & 0.002 \\
\hline \multirow{5}{*}{ Sydney } & Mean-1 & 17.6 & 1125 & 991.2 & 499.2 & 35.1 & 23.3 & 17.9 & 11.2 & 7.3 & 3.8 \\
\hline & Mean-2 & 18.0 & 1281 & 94.0 & 55.1 & 41.9 & 28.6 & 22.2 & 13.8 & 9.0 & 3.9 \\
\hline & Change & $0.4^{\circ} \mathrm{C}$ & $+14 \%$ & $+3 \%$ & $+12 \%$ & $+20 \%$ & $+23 \%$ & $24 \%$ & $+23 \%$ & $+25 \%$ & $+3 \%$ \\
\hline & $t$-test & 4.93 & 1.82 & 0.36 & 1.26 & 1.67 & 1.87 & 2.07 & 2.05 & 2.11 & 0.36 \\
\hline & P-value & $<0.01$ & 0.037 & 0.359 & 0.107 & 0.050 & 0.034 & 0.022 & 0.023 & 0.020 & 0.359 \\
\hline \multirow{5}{*}{ Melbourne } & Mean-1 & 15.1 & 696 & 55.6 & 29.7 & 19.2 & 12.4 & 9.5 & 6.0 & 3.8 & 2.2 \\
\hline & Mean-2 & 15.8 & 622 & 73.3 & 32.5 & 19.6 & 11.9 & 9.1 & 5.8 & 3.5 & 1.9 \\
\hline & Change & $0.7^{\circ} \mathrm{C}$ & $-12 \%$ & $+24 \%$ & $+9 \%$ & $+2 \%$ & $-4 \%$ & $-3 \%$ & $-4 \%$ & $-10 \%$ & $-14 \%$ \\
\hline & $t$-test & 5.61 & 2.25 & 1.85 & 0.69 & 0.12 & 0.27 & 0.29 & 0.37 & 0.82 & 1.16 \\
\hline & P-value & $<0.01$ & 0.014 & 0.035 & 0.249 & 0.453 & 0.396 & 0.388 & 0.356 & 0.208 & 0.125 \\
\hline \multirow{5}{*}{ Hobart } & Mean-1 & 12.3 & 670 & 33.6 & 19.7 & 13.2 & 9.6 & 8.1 & 5.8 & 4.4 & 2.3 \\
\hline & Mean-2 & 13.0 & 572 & 42.7 & 19.0 & 12.0 & 7.8 & 6.4 & 4.3 & 3.2 & 1.8 \\
\hline & Change & $0.7^{\circ} \mathrm{C}$ & $-17 \%$ & $+27 \%$ & $-4 \%$ & $-9 \%$ & $-19 \%$ & $-21 \%$ & $-25 \%$ & $-26 \%$ & $-22 \%$ \\
\hline & $t$-test & 7.97 & 2.79 & 1.69 & 0.33 & 1.00 & 2.56 & 2.8 & 2.78 & 2.65 & 1.73 \\
\hline & P-value & $<0.01$ & 0.004 & 0.049 & 0.373 & 0.161 & 0.007 & 0.004 & 0.004 & 0.006 & 0.045 \\
\hline
\end{tabular}


As can be seen in Table 2, Brisbane rainfall intensities for durations longer than 6 hours have increased significantly. Sydney rainfall intensities increased for durations longer than an hour. Rainfall intensities in Melbourne and Hobart have decreased for longer durations (> 1hr) and have increased for shorter durations $(<1 \mathrm{hr})$. Furthermore, at both sites the temperature increased by approximately 0.7 degree Celsius.

The changes in mean annual rainfall and rainfall intensities with $p$-values less than 0.05 are presented as a percentage change from P1 (Figure 3). The mean 6 minute rainfall intensities in Rockhampton, Melbourne and Hobart have increased significantly, although the mean annual rainfall has decreased significantly from $\mathrm{P} 1$ to $\mathrm{P} 2$. The rainfall intensities for most durations longer than 1 hour show significant changes in Brisbane, Sydney and Hobart and these changes have a positive correlation with changes in the mean annual rainfall (Fig. 3). It is interesting to note that significant changes in longer duration intensities occurred only in the sub-tropical and temperate climate zones.

The mean annual temperature has increased in Eastern Australia, which is in general agreement with global warming trends and findings from previous investigations (Murphy and Timbal 2008; Nicholls 2003). The relationship between the mean annual temperature and the mean 6 minute duration rainfall intensity is positively correlated in Rockhampton (sub-tropical), Melbourne and Hobart (temperate). The mean annual temperatures have increased significantly from $\mathrm{P} 1$ to $\mathrm{P} 2$ in both Sydney and Hobart. Further, mean rainfall intensities for durations longer than one hour increased significantly in Sydney but decreased in Hobart. There is no correlation between mean annual temperature and rainfall intensities for durations between 1 and 24 hours. 


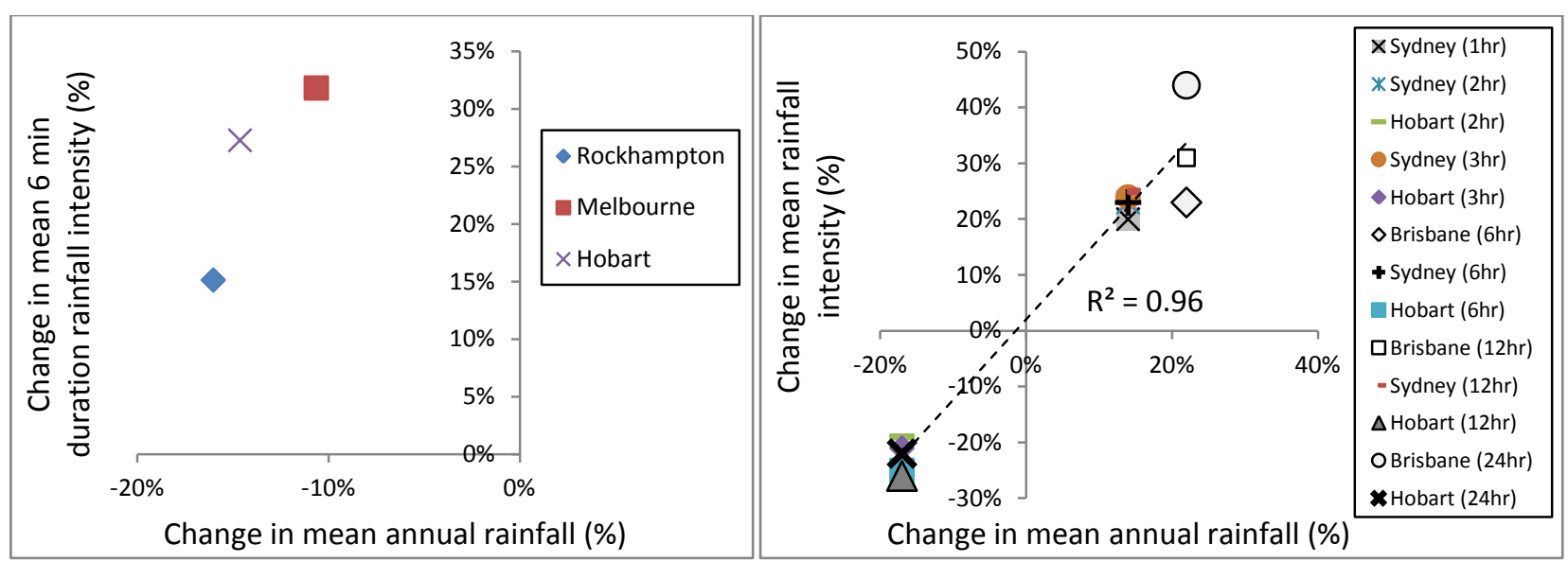

Figure 3 Relationship between changes in mean annual rainfall and those in mean rainfall intensity when P-value $\leq 0.05$ for the six minutes duration (right) and the durations longer than one hour (left).

\section{Conclusions}

Climate data for a 30-year period are commonly used to define a climatology or a baseline for comparative analysis. For this study, we intentionally selected two non-overlapping 30-year periods with the greatest contrast in mean annual rainfall to look for significant changes in short duration rainfall intensities. The aim of this study was to examine the changes in rainfall intensity for different storm durations between two contrasting periods in Eastern Australia. This study produced IFD curves using 6 minutes rainfall data for the two contrasting periods and tested for significant changes in mean temperature, annual rainfall and rainfall intensities. For the two contrasting periods, temperature for the latter period is always higher for all 6 sites, suggesting a warming trend. Change in mean annual rainfall is not consistent in terms of its trend, however, the changes are mostly significant (at 0.05 level) between two contrasting periods. Short duration rainfall intensity shows considerable variability. In general, 6 minutes rainfall intensities have mostly increased, following the trend in temperature. For durations longer than 1 hour, changes 
in rainfall intensity tended to follow those of mean annual rainfall. Significant changes in rainfall intensity at duration $\geq 1$-hr occurred only at non-tropical sites in Eastern Australia. A strong correlation was noted between changes in mean annual rainfall and rainfall intensities for these non-tropical sites.

\section{References}

Australian Bureau of Meteorology. 2011 The Rainfall IFD Data System. Bureau of Meteorology. Blenkinsop, S., Jones, P.D., Dorling, S.R. and Osborn, T.J. 2009 Observed and modelled influence of atmospheric circulation on central England temperature extremes. Int. J. Climatol. 29, 1642-1660.

Cannarozzo, M., Noto, L.V. and Viola, F. 2006 Spatial distribution of rainfall trends in Sicily (1921-2000). Physics and Chemistry of the Earth, Parts A/B/C. 31, 1201-1211.

Canterford, R.P., Pescod, N.R., Pearce, H.J. and Turner, L.H. 2001 Design Intensity-FrequencyDuration Rainfall. In: Australian Rainfall and Runoff (D.H. Pilgrim, ed.). Reprinted ed. The Institution of Engineers, Barton, Australia.

Chow, V.T., Maidment, D.R. and Mays, L.W. 1988 Applied Hydrology. McGraw-Hill series in water resources and environmental engineering. McGraw-Hill, New York, xiii, pp. 572

Endreny, T.A. and Imbeah, N. 2009 Generating robust rainfall intensity-duration-frequency estimates with short-record satellite data. J. Hydrol. 371, 182-191.

Green, J., Xuereb, K., Johnson, F., Moore, G. and The, C. 2012 The Revised IntensityFrequency-Duration (IFD) Design Rainfall Estimates for Australia - An Overview, 34th Hydrology \& Water Resources Symposium. 19-22 November 2012, Engineers Australia, Sydney, Australia, 808-815. 
Groisman, P.Y., Knight, R.W., Easterling, D.R., Karl, T.R., Hegerl, G.C. and Razuvaev, V.N. 2005 Trends in Intense Precipitation in the Climate Record. J. Climate. 18, 1326-1350.

Harvey, S., Hoedt, G.d. and Ernst, J. 2000 Objective classification of Australian climates. Australian Meteorological Magazine, 49, 87-96.

Haylock, M. and Nicholls, N. 2000 Trends in extreme rainfall indices for an updated high quality data set for Australia, 1910-1998. Int. J. Climatol. 20, 1533-1541.

Johnson, F., Xuereb, K., Jeremiah, E. and Green, J. 2012 Regionalisation of rainfall statistics for the IFD Revision Project, 34th Hydrology \& Water Resources Symposium, 19-22 November 2012, Engineers Australia, Sydney, Australia, 185-192.

Krishnakumar, K.N., Prasada Rao, G.S.L.H.V. and Gopakumar, C.S. 2009 Rainfall trends in twentieth century over Kerala, India. Atmospheric Environmeny. 43, 1940-1944.

Li, J., Feng, J. and Li, Y. 2011 A possible cause of decreasing summer rainfall in northeast Australia. Int. J. Climatol. 32, 995-1005.

Lough, J.M. 1991 Rainfall variations in Queensland, Australia: 1891-1986. Int. J. Climatol. 11, 745-768.

Lough, J.M. 1993 Variations of some seasonal rainfall characteristics in Queensland, Australia 1921-1987. Int. J. Climatol. 13, 391-409.

Lough, J.M. 1997 Regional indices of climate variation: temperature and rainfall in Queensland, Australia. Int. J. Climatol. 17, 55-66.

Murphy, B.F. and Timbal, B. 2008 A review of recent climate variability and climate change in southeastern Australia. Int. J. Climatol. 28, 859-879.

Nicholls, N. 2003 Continued anomalous warming in Australia. Geophys. Res. Lett., 30, 1370. 
Nicholls, N. and Kariko, A. 1993 East Australian Rainfall Events: Interannual Variations, Trends, and Relationships with the Southern Oscillation. J. Climate. 6, 1141-1152.

Nicholls, N., Lavery, B., Frederiksen, C., Drosdowsky, W. and Torok, S. 1996 Recent apparent changes in relationships between the El Niño-Southern Oscillation and Australian rainfall and temperature. Geophysical Researcj Letter. 23, 3357-3360.

Pilgrim, D.H. (ed.) 2001. Australian rainfall and runoff: a guide to flood estimation, Institution of Engineers, Australia, Barton.

Pilgrim, D.H. and Doran, D.G. 2001 Flood frequency analysis. In D.H. Pilgrim ed. Australian Rainfall and Runoff. The Institution of Engineers, Australia, Barton.

Rahman, A., Haddad, K., Kuczera, G. and Weinmann, E. 2009, Australian Rainfall and Runoff Revision Projects: Project 5 Regional Flood Methods, Institution of Engineers, Australia, Sydney.

Srikanthan, S. 2012 Annual Maximum or Partial Duration Series: A review, 34th Hydrology \& Water Resources Symposium. 19-22 November, Engineers Australia, Sydney, Australia, 407-414. Suppiah, R. 1993 ENSO phenomenon and 30-50 day variability in the Australian summer monsoon rainfall. Int. J. Climatol. 13, 837-851.

Suppiah, R. and Hennessy, K.J. 1998 Trends in total rainfall, heavy rain events and number of dry days in Australia, 1910-1990. Int. J. Climatol. 18, 1141-1164.

Takeuchi, K. 1984 Annual maximum series and partial-duration series -- Evaluation of Langbein's formula and Chow's discussion. J. Hydrol. 68, 275-284.

Trenberth, K.E. 1998 Atmospheric Moisture Residence Times and Cycling: Implications for Rainfall Rates and Climate Change. Climatic change. 39, 667-694. 
Trenberth, K.E. 1999 Conceptual Framework for Changes of Extremes of the Hydrological Cycle with Climate Change. Climatic change. 42, 327-339.

Trenberth, K.E., Dai, A., Rasmussen, R.M. and Parsons, D.B. 2003 The Changing Character of Precipitation. Bulletin of the American Meteorological Society. 84, 1205-1217.

Vogel, R.M., McMahon, T.A. and Chiew, F.H.S. 1993, Floodflow frequency model selection in Australia, J of Hydrol, 146, 421-449.

Xuereb, K. and Green, J. 2012 Defining Independence of Rainfall Events with a Partial Duration Series Approach, 34th Hydrology \& Water Resources Symposium. 19-22 November 2012, Engineers Australia, Sydney, Australia, 169-176.

Yu, B. and Neil, D.T. 1993 Long-term variations in regional rainfall in the South-West of Western-Australia and the difference between average and high-intensity rainfalls. Int. $J$. Climatol. 13, 77-88. 